\title{
School children's views of asthma services in two contrasting general practice populations
}

Catherine Gleeson Independent Consultant Nurse in School Health and part-time Practice Nurse, West Yorkshire

\begin{abstract}
The Government has identified school as a key setting for reducing health inequalities, but many schools fail to support pupils with medical needs, such as asthma. This paper describes a survey designed to elicit the views of asthmatic children in two contrasting general practitioner (GP) practice populations regarding their asthma care, including support at school. A questionnaire was sent to all asthmatic children aged 4-17 in two practices during August 2002. The population in Practice 1 (P1) was mainly white, suburban, with pockets of deprivation, and had a long-established asthma clinic. Practice 2 (P2) had an almost exclusively Asian population, was close to the town centre and did not have a regular asthma clinic. Children from P1 had a higher response rate, 69 of $124(55 \%)$ (compared with 21 of $107,21 \%$ in P2), they also reported lower symptom levels and less use of hospital services, particularly paediatric outpatient clinics. Nurses were perceived as the main source of information and support in P1 (68\%), followed by doctors (43\%). In P2 this was reversed, nurses being identified by $33 \%$, doctors by $62 \%$. If an asthma problem occurred at school, the vast majority said that they would ask a teacher for help, but they also said that school staff needed more information to help pupils with asthma. These results mirror what is already known from large survey data regarding inequality of access to asthma services. In view of the national shortage of GPs it would seem prudent for Primary Care Organizations to increase investment in delivery of comprehensive asthma management services by practice nurses, school health nurses and pharmacists. This should include support for teachers, who are being expected to cope with increasing numbers of children with medical needs in schools.
\end{abstract}

Key words: asthma; inequalities; schools

\section{Introduction}

The UK Government has identified school as a key setting for reducing health inequalities (Department of Health (DH), 1999) but there has been little investment in school health nursing to support systematic health improvement in all schools (Cotton et al., 2000). The potential for school-based approaches to reduce inequality of access to asthma care has not been fully realized, as shown by a number of indicators in a report by the National Asthma

Address for correspondence: Catherine Gleeson. Email: c.r.gleeson@talk21.com
Campaign (NAC) (NAC, 1999). This included survey data from 4150 'Junior Asthma Club' members which showed that $50 \%$ experienced disturbed sleep on a monthly basis, over $30 \%$ missed more that a week of school per year; $37 \%$ missed some sports lessons because of asthma. The report also showed a lack of commitment by $68 \%$ of Local Education Authorities (LEAs) to provide asthma training for teachers (NAC, 1999).

Certain groups of asthmatic children, such as those from inner city areas, especially those in ethnic minority groups, have been found to be more likely to be under-diagnosed and under-treated (DuranTauleria et al., 1996). Regular review of asthmatic patients has long been recommended and is 
reinforced in National Asthma Guidelines (British Thoracic Society, Scottish Intercollegiate Guidelines Network, 2003). However, it has been known for many years that asthma clinic attendance is very variable (NAC, 2001). In a review paper on targeting asthma services in the UK, it was concluded that conventional patient education services are not easily accessible for those most needy (Watson and Lewis, 1996).

In line with Government policy of encouraging health staff to take account of patients' views (DH, 2000), the initial aim of this study was to carry out a survey of school-aged asthmatic children in the practice in which the author worked as a practice nurse. It was anticipated that this would give insight into the patients' perceptions of a patient friendly and accessible asthma service.

The trigger for the decision to carry out a survey was an experience in April 2001 in which a sporting event for local asthmatic children failed to attract any participants. The event, at which the practice nurse's contribution was to have an information stand, had been organized as part of a wider Local Authority-led Asthma Project directed at providing allergen reduction measures in the home. This experience raised a question: If asthmatic children did not want a fun event at a sports centre, what would they like (if anything) to help them with their asthma?

\section{Method}

Agreement was reached with the practice team to carry out a survey, and three asthmatic patients (aged 11, 11, and 7 years) and their mothers were recruited opportunistically. The three children, assisted by their mothers and the practice nurse, successfully applied for a Local Authority Children's Rights grant to develop and carry out the survey. Based upon the evidence of particular groups of children failing to access good asthma care (DuranTauleria et al., 1996; Watson and Lewis, 1996) another practice with a contrasting population was approached, and was willing to participate (separately funded). Approval from the local Ethics Committee was not required as at the time of the study this was considered to be a practice audit. Patient participation was voluntary, and no individual patients would be identifiable in the results. The study was planned during 2001-2002 at which time audits and 'consumer-view' surveys did not necessarily require approval from Ethics Committees. Since that time the criteria for Research Governance has become more stringent regarding the need for ethical approval.

A structured questionnaire was developed, which covered four aspects: symptoms (using a validated Morbidity Index, Jones et al., 1999); use of health services; sources of information and support; asthma at school. The children's contribution to the questionnaire design was to include their experience of how asthma can affect daily lives, and to make the format appealing to primary and secondary age groups using different artwork. The final version was agreed after piloting with four asthmatic children (not from the survey practices), and comments from practice staff.

At the practice in which the author worked (to be called P1) the population was mainly white, suburban and included some socially deprived areas. A regular asthma clinic service had been run for over seven years and most patients (of all ages including adults) were reviewed by the practice nurse once a year. The contrasting practice (P2), is within the same Primary Care Trust (PCT) area, situated close to the town centre and had a very high proportion of Asian patients. Their practice nurse, who had recently completed the Diploma in Asthma Care course, was keen to find ways of targeting asthma patients, as previous attempts to run an asthma clinic were met with poor attendance. Questionnaires were posted in August 2002 to all children with asthma, aged between 4 and 17 years (125 from P1, 107 from P2).

\section{Results}

Questionnaires were returned by $69(55 \%)$ children from P1, of which $32(46 \%)$ were girls and $37(53 \%)$ were boys. The response rate from $\mathrm{P} 2$ was much lower, at $21(21 \%)$, of which $5(24 \%)$ were girls and $16(76 \%)$ were boys. Results of the four aspects covered in the questionnaire are given below, although there is some overlap between them.

\section{Symptoms}

The Morbidity Index results showed markedly lower symptom levels in P1, but school absence 
levels were similar in both groups, as shown in Table 1.

\section{Use of hospital care and GP home visits}

Use of hospital services during the past year was much lower in P1 patients as shown in Table 2. Home visits by the GP in the past year was similar in both practices.

\section{Perceived sources of asthma information}

In response to the question 'Do you think you understand enough about asthma?' $61 \%$ in P1 said they knew 'a lot', or 'some', slightly more than in P2 (48\%). When asked 'What things have helped you to learn more about your asthma?' various sources were ticked, with parents and family being important to both groups as shown in Table 3.
Perceived health professional sources of information differed, with $\mathrm{P} 1$ patients stating nurses to be the main source, whereas in $\mathrm{P} 2$ it was doctors.

Peak flow meters were available to most children in $\mathrm{P} 1(78 \%)$ and all but one was able to write down their best peak flow reading. In contrast, just three children (14\%) in P2 had a peak flow meter.

\section{Asthma at school}

Around one-third (33\%) in P1, and slightly more $(43 \%)$ in $\mathrm{P} 2$ felt that asthma made them sometimes miss out on activities at school. If an asthma problem occurred at school the vast majority would ask a teacher for help, with various others being identified as shown in Table 4. School nurses were mentioned as a source of support by a high proportion, but around two-thirds (62\% of $\mathrm{P} 1,67 \%$ of P2) did not know when she was available to

Table 1 Morbidity Index results

\begin{tabular}{lll}
\hline Indicator of asthma control & $\mathrm{P} 1$ patients, $n=69(\%)$ & $\mathrm{P} 2$ patients, $n=21(\%)$ \\
\hline $\begin{array}{l}\text { Being in a wheezy or asthmatic condition at } \\
\text { least once a week (in the past four weeks) }\end{array}$ & $17(25)$ & $15(71)$ \\
Wheezing during the night (in the past four weeks) & $17(25)$ & $11(52)$ \\
School absence due to asthma (in the past four weeks) & $12(20)$ & $5(24)$ \\
\hline
\end{tabular}

Table 2 Use of hospital services and home visits in the past year

\begin{tabular}{lll}
\hline Use of services & P1 patients, $n=69(\%)$ & P2 patients, $n=21(\%)$ \\
\hline Use of A\&E in the past year & $11(16)$ & $5(24)$ \\
Hospital admission in the past year & $4(6)$ & $5(24)$ \\
Paediatric outpatient clinic in the past year & $7(10)$ & $6(28)$ \\
Home visit by GP in past year & $7(10)$ & $2(9)$ \\
\hline
\end{tabular}

Table 3 Perceived sources of asthma information

\begin{tabular}{llr}
\hline Source & P1 patients, $n=69(\%)$ & P2 patients, $n=21(\%)$ \\
\hline Discussing with parents or family members & $51(74)$ & $11(52)$ \\
Discussing with nurses & $47(68)$ & $7(33)$ \\
Discussing with doctors & $30(43)$ & $13(62)$ \\
Leaflets on asthma and/or inhalers & $29(42)$ & $6(29)$ \\
From school nurses & $13(19)$ & $3(14)$ \\
From teachers & $4(6)$ & $0(0)$ \\
Using the Internet & $3(4)$ & $1(5)$ \\
From videos & $4(6)$ & $2(10)$ \\
\hline
\end{tabular}


Table 4 Perceived sources of asthma support at school

\begin{tabular}{lll}
\hline Source & $\begin{array}{l}\text { P1 patients, } \\
n=69(\%)\end{array}$ & $\begin{array}{l}\text { P2 patients, } \\
n=21(\%)\end{array}$ \\
\hline Teachers & $54(78)$ & $19(90)$ \\
School nurses & $43(62)$ & $17(81)$ \\
Friends & $38(55)$ & $10(48)$ \\
Dinner ladies & $33(48)$ & $9(43)$ \\
Secretaries & $30(43)$ & $8(38)$ \\
\hline
\end{tabular}

them. Few could correctly name their school nurse (22\% from P1, 9\% from P2) and some participants inadvertently named other members staff (such as secretary, lunchtime supervisor, form tutor) as a school nurse.

Around half (45\% in P1, 57\% in P2) felt that staff at school knew enough to help a child with asthma problems. But a high proportion (75\% in $\mathrm{P} 1,90 \%$ in P2) also said that school staff needed more information to help pupils with asthma. The majority (51\% in $\mathrm{P} 1,67 \%$ in $\mathrm{P} 2$ ) would like an asthma nurse to visit their school for review and information, but a few said that they would not $(17 \%$ in $\mathrm{P} 1,10 \%$ in P2). Children attended a wide variety of schools (including state and independent sector), 25 in all from P1 (eight secondary schools, two sixth form, 14 primary and one 3-18 years) and 13 from P2 (six secondary, two sixth form, five primary).

\section{Discussion}

\section{Methodical issues}

A pragmatic approach was taken to eliciting the views of asthmatic children in two contrasting GP populations. The response rate differed markedly between the practices and it is a limitation of the study that nonrespondents were not followed up due to lack of resources. However, the difference in response rate is relevant. One of the reasons for this difference may be that children in P1 were motivated to respond as they were used to being involved in managing their asthma through the system of regular review. It is suggested that they anticipated that their views were of interest and would be taken seriously. The low response rate in $\mathrm{P} 2$ was unsurprising as it is frequently acknowledged by practice nurses that patient attendance for various clinic appointments is generally poor in ethnic minority communities.

\section{Consumer view}

The results consist of a 'consumer view', as encouraged by Government policies (DH, 2000). The aspects covered by the questionnaire were informed from the start by the views of three volunteer asthmatic patients regarding areas which they felt to be relevant. The exception to this was the Morbidity Index questions, which had been validated for routine use in routine general practice in a previous study by Jones et al. (1999).

Respondents have reflected what is already known from national survey data regarding symptom levels. That is, patients in P2 whose care was opportunistic rather than planned had symptom levels similar to those reported nationally (NAC, 1999). In contrast, patients in P1 who had access to a regular and reliable asthma clinic had lower symptom levels. They also reported far less use of hospital services (particularly paediatric outpatients).

\section{Perceived sources of information and support}

Parents and family members were identified by children from both practices as important sources of information and support. This was an anticipated finding, consistent with the results of large annual surveys of health-related behaviour (Balding, 2001). However, differences were perceived regarding contact with nurses and GPs, in that nurses were viewed as the main source of information and support in $\mathrm{P} 1$. In contrast, the respondents in $\mathrm{P} 2$ saw the GP being the main contact for asthma, a finding which is consistent with a national audit of asthma (NAC, 2001). In the face of current GP shortages in the NHS it is unlikely that GPs can give adequate time to meet the educational needs of asthmatic patients. The new General Medical Services (nGMS) contract, with its payment for quality aspects of management of long-term conditions, should help to stimulate investment in asthma training for nurses to increase their input into asthma clinic work. This, together with fulfilling the organizational requirements of the nGMS contract (i.e., compiling and maintaining a register, and organizing annual reviews of asthmatic patients) should improve access to good quality asthma care.

The school nurse was mentioned by some children as another source of information and support. There is potential for school nurses to work more closely with GP practices, for example by carrying out asthma reviews in school for those children 
who fail to attend their practice appointment. Alternatively, if not adequately trained themselves they could facilitate access into school by a diploma-trained practice nurse. This kind of intervention could be viewed as an example of a flexible and well-targeted approach which would fit in with the patients' pathway of care, as recommended by Chapman et al. (2004) in their systematic review of recent innovations to improve access to primary care. Most GPs know little of what school nurses do but a survey of 148 GPs has indicated that they would welcome closer working (Richardson-Todd, 2002). Some examples of how school nurses could work with GP practices are given elsewhere (Gleeson, 2004).

\section{Asthma at school}

Approximately one-third of children felt that their asthma made them sometimes miss out on activities at school, a similar proportion to that reported nationally (NAC, 1999). Although teachers were identified as the main source of help for children if they had asthma problems at school, respondents also felt that teachers needed more information. The LEA had, in the past, organized an annual training day for teachers on asthma, diabetes and epilepsy, but this had not been run for over six years (personal communication with School Effectiveness Service). This is not unusual, as the NAC (1999) has reported a lack of commitment by over two-thirds of LEAs to train school staff. Failure of the wellintentioned LEA Asthma Project (which was the stimulus for this survey) to reach its intended audience is not an uncommon occurrence nationally. This is apparent from numerous anecdotal accounts, and also from a report on 84 (of 99) English Health Improvement Programmes which showed that many projects lacked targets or outcomes (NSPCC et al., 2001).

The findings indicated that a variety of school staff, such as dinner ladies and secretaries, were also seen as sources of asthma support. This has training implications. The NAC recognizes the need for training to be inclusive of all school staff (NAC, 1999) and recommends that LEAs work with Primary Care Organizations to ensure that appropriate training is delivered.

The National Healthy Schools Standard (NHSS), with its emphasis on 'whole school approaches', provides a vehicle for such training in partnership with the wider primary health care team (Department for Education and Skills (DfES), 1999). The NHSS is a joint DfES/DH programme which is part of the Government's strategy to reduce inequalities in health and education. Although no funding is attached to achievement of the NHSS Award, the Government is encouraging schools to sign up and currently it is reported that over 10000 schools are involved (DfES, 2004). Examples of how the NHSS could be developed to increase children's empowerment to cope with long-term conditions such as asthma are discussed elsewhere (Gleeson, 2004).

The recently published National Service Framework (NSF) for children (DH, 2004a) has used asthma to illustrate how NSF standards can be achieved. The Asthma Exemplar (DH, 2004b) describes how partnership working between education, NHS, social services and the voluntary sector, can achieve standards set out in the NSF. A role for school nurses is featured throughout the document (DH, 2004b). However, it is known that only around $10 \%$ of children have access to a school nurse (Gleeson et al., 2002), so if the NSF standards are to be achieved there will need to be a substantial increase in investment in nursing workforce, training and organizational support.

\section{Reducing health inequalities}

Both study practices were similarly resourced in terms of having a nurse with Diploma in Asthma Care training, but previous efforts to run an asthma clinic in P2 had been abandoned due to low attendance. Reasons for the failure of particular communities to access services appropriately are complex and wide ranging, as discussed in the review of access mentioned earlier (Chapman et al., 2004). The authors concluded that interventions aimed at improving access for deprived groups should be based upon locally defined needs and evaluated within the context of the whole care pathway. It has also been argued (Abbott, 2003) that the strategies in the NHS Plan are directed more towards improving absolute access (quicker GP appointments, NHS Direct, walk-in centres) rather than relative access (for deprived groups in particular). School nurses have been identified as key professionals in contributing to reducing health inequalities $(\mathrm{DH}$, 1999). Ensuring that all school children receive the health care they need is one example of narrowing the inequalities gap. 
Very few children in this survey had used the Internet as a resource for asthma information. It is suggested that there is untapped potential for practice nurses, school nurses (also perhaps teachers and school librarians) to facilitate children's access to websites of patient support organizations for long-term conditions such as asthma, diabetes and epilepsy.

\section{Conclusions}

Children perceive not only their GP practice as the place for asthma support, but also their families, various school staff and school nurses. In view of this, perhaps a broader approach is needed in which nurses provide a flexible service for asthma management. This could include carrying out asthma reviews in school for those children who have, for whatever reason, not had their asthma monitored at their GP practice. The review could be documented on a paper version of the practice Asthma Template, and entered later at a convenient time into the child's medical record.

In areas, such as the $\mathrm{P} 2$ practice, where attendance for clinics is poor, there are a number of 'whole-practice' approaches which could improve patients' attendance. These include: having clinic times which suit children (such as after school and during holidays); offering sequential or joint appointments for siblings and parents; use of message systems on the practice computer so that receptionists can prompt patients to book in for an asthma checkup when they attend for other things (repeat prescriptions, immunizations).

The seamless functioning of asthma care is a challenge which has not been fully met regarding transfer of information between primary and secondary care (Johnson et al., 1998; Royal College of Physicians, 1999). Improvements could be made by adopting 'whole-practice' approaches such as: use of a personalized written asthma action plan to help patients understanding of how to manage their condition (in spite of asthma action plans being long recommended, implementation is minimal, NAC, 2001); routinely informing the practice nurse of any patients who have had hospital admission or accident and emergency (A\&E) attendance; accurate READ coding so that staff can easily see which patients need review; GPs referring patients to the asthma clinic within a month or so following an exacerbation; recording the child's current school on their medical record - this could be useful for organizing a school-based session for reviews if several are found to be at the same school.

Asthma is just one example of a long-term condition in which empowerment of the young person is key to successful management. It has been recommended that a proactive approach be taken to help young people become more familiar with local health services in order to increase their confidence in using them (Donovan et al., 1997; Balding, 2001). This confidence could influence the child's future use of other GP services, such as immunization or sexual health, and could be of particular benefit in areas of social deprivation.

\section{Areas for future research}

Service delivery and organization is an area in which more research is needed to clarify the relative success of different models of provision for the school age population. Whatever model is tested it is essential that outcomes are measured across the whole care pathway, including costs of patient education, medication and use of hospital services. Examples which could be tested include: use of facilitated access for pupils with long-term conditions to websites of appropriate patient support organizations (within school libraries); effectiveness of different facititators to such websites (school nurses, teachers, librarians, practice nurses); carrying out routine asthma reviews in school setting for those children who fail to attend GP practice review.

\section{Acknowledgement}

Thanks are due to the Yorkshire Practice Nurse Association for funding to enable this work to be done.

\section{References}

Abbott, S. 2003: Equity of access to primary care in the UK: is it likely to increase? [Editorial]. Primary Health Care Research and Development 4, 187-89.

Balding, J. 2001: Young people in 2000: the health related behaviour questionnaire results for 42,073 young people between the ages of 10 and 15. Schools Health Education Unit, Exeter.

British Thoracic Society, Scottish Intercollegiate Guidelines Network. 2003: British guideline on the management of asthma. Thorax Supplement 58, 1-94. 
Chapman, J., Zechel, A., Carter, Y. and Abbott, S. 2004: Systematic review of recent innovations in service provision to improve access to primary care. British Journal of General Practice 54, 374-81.

Cotton, L., Brazier, J., Hall, D.M.B., Lindsay, G., March, P., Polnay, L. and Williams, T.S. 2000: School nursing: costs and potential benefits. Journal of Advanced Nursing 31, 1063-71.

Department for Education and Skills. 1999: National healthy school standard guidance. Nottingham: DfES Publications.

Department for Education and Skills. 2004: Healthy living blueprint for schools. Nottingham: DfES Publications.

Department of Health. 1999: Saving lives: our healthier nation. London: The Stationery Office.

Department of Health. 2000: The NHS Plan. A plan for investment. A plan for reform. London: The Stationery Office.

Department of Health. 2004a: National service framework for children, young people and maternity services. London: The Stationery Office.

Department of Health. 2004b: Asthma examplar, national service framework for children, young people and maternity serivces. London: The Stationery Office.

Donovan, C., Mellanby, A., Jacobson, L., Taylor, B. and Tripp, J. 1997: Teenagers' views on the general practice consultation and provision of contraception. British Journal of General Practice 47, 715-18.

Duran-Tauleria, E., Rona, R., Chinn, S. and Burney, P. 1996: Influence of ethnic group on asthma treatment in children in 1990-1: national cross sectional study. British Medical Journal 313, 148-52.

Gleeson, C. 2004: School health nursing - evidence-basedpractice? Primary Health Care 14, 38-41.
Gleeson, C., Robinson, M. and Neal, R. 2002: A review of teenagers' perceived needs and access to primary health care - implications for health services. Primary Health Care Research and Development 3,184-93.

Johnson, P., Wilkinson, I., Sutherland, A., Johnston, I. and Hall, I. 1998: Improving communication between hospital and primary care increases follow-up rates for asthmatic patients following casualty attendance. Respiratory Medicine 92, 289-91.

Jones, K., Cleary, R. and Hyland, M. 1999: Predictive value of a simple asthma morbidity index in a general practice population. British Journal of General Practice 49, 23-26.

National Asthma Campaign. 2001: Out in the open - a true picture of asthma in the United Kingdom today. The Asthma Journal Special Supplement 6,1-14.

National Asthma Campaign. 1999: Danger Zone - a NAC report on how schools can be made safer for children with asthma.

NSPCC in association with The Children's Society, National Children's Bureau, Barnardo's and NCH. 2001: Improving Children's Health (2) - An analysis of Health Improvement Programmes (2000-2003). London: National Society for the Prevention of Cruelty to Children.

Richardson-Todd, B. 2002: GPs: do they know what school nurses do? Primary Health Care 12,38-41.

Royal College of Physicians. 1999. Measuring Clinical Outcome in Asthma - A patient-focussed approach. London: Royal College of Physicians.

Watson, J. and Lewis, R. 1996: Asthma care: are we hitting the target? The Asthma Journal 1, 318-22. 